\title{
A pre-evaluation of psychological factors may positively affect the outcomes of smoking cessation treatments: A comparison in terms of smoking behavior
}

\author{
Sebahat Gücük', Burcu Rahşan Erim², Mehmet Kayhan
}

\begin{abstract}
INTRODUCTION The aim of this study was to compare smoking behavior in out-patients in terms of psychological factors with a view to supporting cessation treatment. METHODS We conducted a cross-sectional and analytical study through face-toface interviews by the primary care physician with 765 volunteer participants who applied to our hospital for any reason between March and July 2019. The questionnaire administered had two parts: questions about sociodemographic characteristics and usage of tobacco and tobacco products, and questions of the UCLA Loneliness Scale, Multidimensional Scale of Perceived Social Support (MSPSS), Warwick-Edinburgh Mental Wellbeing Scale (WEMBS), and Fagerström Test for Nicotine Dependence (FTND).

RESULTS The study was completed with 765 participants of which $53.1 \%(n=406)$ were female and $46.9 \%(n=359)$ male. Multidimensional perceived social support scale mean score of the participants was $69.9 \pm 15.2(\min =12, \max =84)$. There was a significant relation between mean MPSS and mean WEMBS $(\mathrm{p}<0.05)$. As nicotine scores increased, the mean scores both in MPSS and WEMBS decreased $(\mathrm{p}<0.05)$.

CONCLUSIONS We suggest that the results of the psychometric preliminary evaluations should be customized for individuals applying to smoking cessation clinics and that including the individual's close social connections in the process can facilitate the decision to quit, thus increase smoking cessation rates.
\end{abstract}

\section{AFFILIATION \\ 1 Department of Family Medicine, Faculty of Medicine, Abant İzzet Baysal University, Bolu, Turkey 2 Department of Psychiatry, Faculty of Medicine, Bolu Abant Izzet Baysal University, Bolu, Turkey \\ CORRESPONDENCE TO \\ Sebahat Gücük. Department of Family Medicine, Faculty of Medicine, Abant İzzet Baysal University, 14030, Bolu, Turkey. E-mail: sebahatgu@yahoo.com}

\section{KEYWORDS}

smoking cessation, social support, mental health, well-being, smoking, tobacco control

Received: 29 July 2020

Revised: 25 November 2020

Accepted: 12 December 2020

\section{INTRODUCTION}

According to the data published by World Health Organization (WHO), smoking-related health problems are among the most important preventable causes of mortality and morbidity. In Turkey, $42.7 \%$ of the male and $13.5 \%$ of the female population are smokers. These proportions vary according to country, but are still significant worldwide ${ }^{1}$. It is one of the most important health problems today. People do not or cannot quit in spite of their knowledge of the serious diseases it may cause. Even following medical advice to definitely quit, many people believe they cannot live without smoking out of a fear of feeling emptiness, losing ability to focus, compromising work efficiency, or experiencing difficulty in selfexpression ${ }^{2,3}$.

It is assumed that nicotine addiction and the difficulty of smoking cessation are based on genetic and environmental factors, besides the psychopharmacological effects of nicotine ${ }^{4}$. Other important factors influencing inability to quit include personal characteristics, such as socioeconomic status and personality traits ${ }^{4,5}$. With its stimulating properties, nicotine is particularly attractive to persons who may trade immediate smaller rewards, due to the increase in alertness and taste value it provides, for long-term better health. Addiction is based on the fact that individuals who choose to 
smoke ignore a healthier and more valuable life in the future for these immediate effects of nicotine ${ }^{6}$. Loneliness is a situation anyone can experience at some point in life and it should also be considered in preventive medicine. After all, studies show that individual loneliness can take its toll on society as well as on the individual as far as health sciences are concerned ${ }^{7}$.

Studies focusing on smoking cessation have found that the social support and social network available to the individual plays a part in the decision to quit and the long-term success of smoking cessation. The source of the social support, the number of supporters and their degree of closeness to the receiving individual are important for the success of social support ${ }^{8,9}$.

Subjective wellbeing is connected to a variety of other factors including general lifestyle, health, and social and economic conditions ${ }^{10,11}$.

The reason why the rate of success is lower than expected, in spite of the desire to quit smoking, is primarily associated with unplanned, repetitive attempts at cessation without appropriate treatment support. In the examination of applications to health centers, it was observed that smokers generally have social circles consisting of other smokers with whom they shared a sense of belonging away from unwanted life circumstances ${ }^{8}$. It was found that a new social circle with non-smokers or ex-smokers may boost confidence and help structure the social and medical support appropriately, which in turn would reflect positively on the success and duration of the smoking cessation process ${ }^{9}$.

Consequently, this study was conducted with the aim of comparing smoking behavior in out-patients in terms of psychological factors with a view to supporting cessation treatment studies.

\section{METHODS}

This is a cross-sectional and analytical study conducted through face-to-face interviews by the primary care physician with 765 consenting volunteer participants who applied to our hospital in the city center of Bolu, Turkey, for any reason between March and July 2019.

The questionnaire filled in through face-to-face interviews consisted of two parts: 1) 16 questions on sociodemographics and consumption of tobacco and tobacco products, and 2) questions of the
UCLA Loneliness Scale, Multidimensional Scale of Perceived Social Support (MSPSS), WarwickEdinburgh Mental Wellbeing Scale (WEMBS), and the Fagerström Test for Nicotine Dependence (FTND).

Smoking status was defined as follows.

Non-smoker: smoked $<100$ cigarettes in total in their lifetime.

Ex-smoker: smoked $\geq 100$ cigarettes in total in the past, but quit more than 1 year ago.

Smoker: regardless of regular or irregular consumption, those who smoked $\geq 100$ cigarettes in total were accepted as smokers ${ }^{12}$.

The categories formed in classifying the household members were: 'alone', 'partner', 'extended family', and 'roommate'; people living as part of the same family except for the partner (own children, elderly in the family, sibling[s] of a partner, etc.) were defined as the 'extended family'.

Our study was conducted on a voluntary basis and individuals excluded from the study were: those with a severe communication problem that could interfere with responding to the questionnaire, those who avoided answering some questions due to their content or who were not able to complete all questions for lack of time $(n=122)$, and those receiving psychiatric treatment for any reason. Ethical approval was obtained from the Bolu Abant Izzet Baysal Clinical Ethics Committee (Resolution No: $2018 \backslash 25)$.

\section{UCLA Loneliness Scale}

UCLA Loneliness Scale consists of 20 items, 10 of which are reverse-scored. Each item is scored between 1-4. Loneliness score is calculated by reverting the points given in the reverse-scored items. Possible scores are between 20-80. Higher scores indicate loneliness, lower scores are indicative of not being lonely ${ }^{13}$.

\section{Multidimensional Scale of Perceived Social Support (MPSS)}

This is a scale consisting of 12 items. It is arranged in 3 groups (each subdivided into 4 items) about the source of support: family, friends, and a significant other. Each item is rated using a 7-degree scale. In this study, the scores for the 4 items in each subscale were added to obtain the subscale scores, which were then summed to 
obtain the total score of the scale. A high score indicates a high level of perceived social support ${ }^{14}$.

\section{Warwick-Edinburgh Mental Wellbeing Scale (WEMBS)}

This consists of 14 items and is about the positive mental health of individuals, covering both psychological and subjective wellbeing. It is a 5-point Likert-type scale with a possible minimum score of 14 and maximum of 70 . The scale is: $1=$ definitely disagree, $2=$ disagree, $3=$ somewhat agree, $4=$ agree, and $5=$ completely agree ${ }^{15}$.

\section{Fagerström Test for Nicotine Dependence (FTND)}

This consists of 6 questions. The lowest score is 0 and the highest is 10 points, with higher scores indicating higher levels of dependence. Degrees of dependence according to FTND score are: very low (0-2), low (3-4), medium (5-6), high (7-8), and very high $(9-10)^{16}$.

\section{Statistical analysis}

The analyses were performed using the Statistical Package for Social Sciences 25.0 for Windows (SPSS Inc. Chicago, Illinois, US). Continuous data are expressed as mean \pm standard deviation and categorical variables are presented as frequency and percentage. Demographic variables and scale scores were compared according to the participant's smoking status using different statistical tests. The categorical variables were analyzed using chi-squared or Fisher's exact tests. As the continuous variables were not normally distributed non-parametric Kruskall-Wallis and Mann-Whitney U tests were applied. In addition to the univariate analysis, multivariate analysis was conducted using multiple logistic regression model and risk factors for smoking were assessed with odds ratios (ORs). The results were assessed at a level of $\mathrm{p}<0.05$ significance.

\section{RESULTS}

The study was completed with 765 participants. Mean age was $36.02 \pm 15.23$ years in females and $34.84 \pm 17.07$ years in males. Of the participants, $53.1 \%$ were female $(n=406)$ and $46.9 \%(n=359)$ were male; $50.7 \%(n=359)$ were high school graduates; while $70.2 \%(n=537)$ were married; and $65.1 \%$ were in active employment $(n=498)$. Table 1 shows the sociodemographic characteristics of the participants.

As for the smoking status, $27.5 \%(n=210)$ were smokers and $19.6 \%(n=150)$ were ex-smokers. Among males, the proportion of smokers was significantly $(\mathrm{p}=0.03)$ higher than for females, at $30.1 \%(n=108)$. Mean FTND score was 8.31 1.62 . Of the participants, $53.7 \%(n=411)$ were in the same space as smokers during their breaks at work.

Smoking was more prevalent among married people, males, and others as the level of education increased $(\mathrm{p}<0.001, \mathrm{p}=0.003, \mathrm{p}<0.001$, respectively). Table 2 shows other comparisons regarding smoking status.

Assessing the groups in terms of smoking status, non-smokers had a higher mean score than the other two groups in MPSS $(p<0.002)$. As for the subgroups, the significant other sub-score was higher in non-smokers than the other two groups $(\mathrm{p}=0.027)$ (Table 3$)$.

There was a significant relation between mean MPSS and mean WEMBS $(\mathrm{p}<0.05)$. As nicotine scores increased, the mean scores both in MPSS and WEMBS decreased $(\mathrm{p}<0.05)$.

Coding the participants according to smoking status as smokers and non-smokers (including

Table 1. Sociodemographic characteristics of participants

\begin{tabular}{|c|c|c|c|}
\hline Characteristics & Categories & $n$ & $\%$ \\
\hline \multirow[t]{2}{*}{ Sex } & Female & 406 & 53.1 \\
\hline & Male & 359 & 46.9 \\
\hline \multirow[t]{3}{*}{ Education } & Primary school & 113 & 14.8 \\
\hline & High school & 388 & 50.7 \\
\hline & $\begin{array}{l}\text { Undergraduate or } \\
\text { higher }\end{array}$ & 264 & 34.5 \\
\hline \multirow[t]{2}{*}{ Marital status } & Married & 537 & 70.2 \\
\hline & Single & 228 & 29.8 \\
\hline \multirow{3}{*}{$\begin{array}{l}\text { Employment } \\
\text { status }\end{array}$} & Active employment & 498 & 65.1 \\
\hline & $\begin{array}{l}\text { No active } \\
\text { employment }\end{array}$ & 208 & 27.2 \\
\hline & Student & 59 & 7.7 \\
\hline \multirow[t]{4}{*}{ Household } & Alone & 117 & 15.3 \\
\hline & Partner & 347 & 45.4 \\
\hline & Extended family & 201 & 26.3 \\
\hline & Roommate & 100 & 13.1 \\
\hline \multirow{2}{*}{$\begin{array}{l}\text { Continuous } \\
\text { illness status }\end{array}$} & Yes & 127 & 16.6 \\
\hline & No & 637 & 83.4 \\
\hline
\end{tabular}


Table 2. Comparison of characteristics based on smoking status

\begin{tabular}{|c|c|c|c|c|c|}
\hline Characteristics & Categories & $\begin{array}{c}\text { Smoker } \\
\left(\begin{array}{c}N=210) \\
n(\%)\end{array}\right.\end{array}$ & $\begin{array}{c}\text { EX-smoker } \\
\left(\begin{array}{c}\mathrm{N}=150) \\
n(\%)\end{array}\right.\end{array}$ & $\begin{array}{c}\text { Non-smoker } \\
\begin{array}{c}(\mathrm{N}=405) \\
n(\%)\end{array}\end{array}$ & $p *$ \\
\hline \multirow[t]{2}{*}{ Sex } & Female & $102(25.1)$ & $66(16.3)$ & $238(58.6)$ & 0.003 \\
\hline & Male & $108(30.1)$ & $84(23.4)$ & $167(46.5)$ & \\
\hline \multirow[t]{3}{*}{ Education } & Primary school & $32(28.3)$ & $12(10.6)$ & $69(61.1)$ & $<0.001$ \\
\hline & High school & $83(21.4)$ & $120(30.9)$ & $185(47.7)$ & \\
\hline & Undergraduate or higher & $95(27.5)$ & $18(19.6)$ & $151(52.9)$ & \\
\hline \multirow[t]{2}{*}{ Marital status } & Married & $177(33.0)$ & $132(24.6)$ & $228(42.5)$ & $<0.001$ \\
\hline & Single & $33(14.5)$ & $18(7.9)$ & $177(77.6)$ & \\
\hline \multirow[t]{3}{*}{ Employment status } & Active employment & $161(32.3)$ & $96(19.3)$ & $241(48.4)$ & 0.001 \\
\hline & No active employment & $39(18.8)$ & $42(20.2)$ & $127(61.1)$ & \\
\hline & Student & 10 (16.9) & $12(20.3)$ & $37(47)$ & \\
\hline \multirow[t]{4}{*}{ Household } & Alone & $62(53.0)$ & $0(0)$ & $55(13.6)$ & $<0.001$ \\
\hline & Partner & $90(25.9)$ & $115(33.1)$ & $142(40.9)$ & \\
\hline & Extended Family & $43(21.4)$ & $18(9.0)$ & $140(69.7)$ & \\
\hline & Roommate & $15(15.0)$ & $17(17.0)$ & $68(68.0)$ & \\
\hline \multirow[t]{2}{*}{ Continuous illness status } & Yes & $50(39.1)$ & $18(14.1)$ & 60 (46.9) & 0.004 \\
\hline & No & $160(25.1)$ & $132(20.7)$ & $345(54.2)$ & \\
\hline \multirow[t]{2}{*}{ Passive smoking } & Yes & $155(37.7)$ & $132(32.1)$ & $124(30.2)$ & $<0.001$ \\
\hline & No & 55 (15.5) & $18(5.1)$ & $281(79.4)$ & \\
\hline \multirow[t]{3}{*}{ Alcohol consumption } & Yes & $25(100)$ & $0(0.0)$ & $0(0.0)$ & $<0.001$ \\
\hline & Ex-consumer & $146(21.0)$ & 144 (20.7) & 405 (58.3) & \\
\hline & No & 39 (86.7) & $6(13.3)$ & $0(0.0)$ & \\
\hline
\end{tabular}

${ }^{*} \mathrm{p}<0.05$.

Table 3. Comparison of the mean scores of the Multidimensional Scale of Perceived Social Support (MSPSS), UCLA Loneliness Scale, and Mental Wellbeing Scale, based on smoking status in patient groups

\begin{tabular}{|c|c|c|c|c|}
\hline Scales & $\begin{array}{c}\text { Smoker }(\mathrm{N}=210) \\
\text { Mean } \pm \mathrm{SD}\end{array}$ & $\begin{array}{c}\text { Ex-smoker }(\mathrm{N}=150) \\
\text { Mean } \pm \mathrm{SD}\end{array}$ & $\begin{array}{c}\text { Non-smoker }(\mathrm{N}=405) \\
\text { Mean } \pm \text { SD }\end{array}$ & $p *$ \\
\hline MSPSS & $69.1 \pm 16.2$ & $68.8 \pm 13.4$ & $72.4 \pm 14.3$ & 0.002 \\
\hline Family subscale & $23.1 \pm 5.6$ & $22.6 \pm 5.4$ & $24.9 \pm 4.8$ & $<0.001$ \\
\hline Roommate subscale & $22.6 \pm 5.8$ & $22.6 \pm 5.0$ & $23.4 \pm 5.2$ & 0.101 \\
\hline Significant other subscale & $23.4 \pm 5.8$ & $23.6 \pm 4.2$ & $24.1 \pm 5.31$ & 0.027 \\
\hline UCLA Loneliness & $41.2 \pm 10.4$ & $38.1 \pm 9.4$ & $38.9 \pm 8.3$ & 0.037 \\
\hline Mental Wellbeing & $57.1 \pm 10.0$ & $57.7 \pm 9.5$ & $58.6 \pm 9.9$ & 0.119 \\
\hline
\end{tabular}

*Statistically significant at $\mathrm{p}<0.05$. SD: standard deviation.

ex-smokers), it was found that the probability of smoking among primary school graduates was higher than high school graduates, and 3.4 times higher for those married compared to single. Increased loneliness score significantly increased the probability of smoking (Table 4). 
Table 4. Multiple logistic regression analysis results in the evaluation of the risk factors affecting smoking

\begin{tabular}{|c|c|c|c|c|c|c|c|}
\hline Variables & $B$ & S.E. & Wald & $d f$ & $p$ & OR & $95 \% \mathrm{CI}$ \\
\hline Age & 0.000 & 0.006 & 0.000 & 1 & 0.997 & 1.000 & $(0.989-1.012)$ \\
\hline \multicolumn{8}{|l|}{ Gender } \\
\hline Male (Ref.) & & & & & & 1 & \\
\hline Female & -0.252 & 0.189 & 1.775 & 1 & 0.183 & 0.777 & $(0.537-1.126)$ \\
\hline \multicolumn{8}{|l|}{ Education } \\
\hline Primary school (Ref.) & & & & & & 1 & \\
\hline High school & -0.910 & 0.344 & 7.010 & 1 & 0.008 & 0.402 & $(0.205-0.789)$ \\
\hline Undergraduate or higher & -0.692 & 0.352 & 3.863 & 1 & 0.049 & 0.501 & $(0.251-0.998)$ \\
\hline \multicolumn{8}{|l|}{ Marital status } \\
\hline Single (Ref.) & & & & & & 1 & \\
\hline Married & 1.236 & 0.368 & 11.278 & 1 & 0.001 & 3.443 & $(1.673-7.083)$ \\
\hline \multicolumn{8}{|l|}{ Employment status } \\
\hline \multicolumn{8}{|l|}{ In active employment (Ref.) } \\
\hline No active employment & -0.487 & 0.225 & 4.684 & 1 & 0.030 & 0.614 & $(0.395-0.955)$ \\
\hline Student & -1.728 & 0.481 & 12.897 & 1 & $<0.001$ & 0.178 & $(0.069-0.456)$ \\
\hline \multicolumn{8}{|l|}{ Household } \\
\hline Alone (Ref.) & & & & & & 1 & \\
\hline Partner & -1.628 & 0.301 & 29.245 & 1 & $<0.001$ & 0.196 & $(0.109-0.354)$ \\
\hline Extended family & -1.983 & 0.308 & 41.516 & 1 & $<0.001$ & 0.138 & $(0.075-0.252)$ \\
\hline Roommate & -1.120 & 0.439 & 6.519 & 1 & 0.011 & 0.326 & $(0.138-0.771)$ \\
\hline \multicolumn{8}{|l|}{ Continuous illness } \\
\hline No (Ref.) & & & & & & 1 & \\
\hline Yes & 0.641 & 0.250 & 6.565 & 1 & 0.010 & 1.898 & $(1.163-3.098)$ \\
\hline Family subscale score & -0.046 & 0.028 & 2.610 & 1 & 0.106 & 0.955 & $(0.904-1.010)$ \\
\hline Roommate subscale score & 0.059 & 0.039 & 2.264 & 1 & 0.132 & 1.061 & $(0.982-1.146)$ \\
\hline Significant other subscale score & -0.012 & 0.038 & 0.100 & 1 & 0.752 & 0.988 & $(0.917-1.065)$ \\
\hline UCLA Loneliness score & 0.023 & 0.009 & 6.305 & 1 & 0.012 & 1.024 & $(1.005-1.042)$ \\
\hline
\end{tabular}

B: regression coefficient. Statistically significant at $p<0.05$. Ref.: reference category.

\section{DISCUSSION}

Successful smoking cessation is important for the prevention of tobacco-related diseases with high mortality and morbidity ${ }^{17}$. Cultural characteristics and perceptions of loneliness may hinder open expression of feelings and limit the subject matter into the realm of science, i.e. psychiatry and psychology ${ }^{18}$.

In the general population, prevalence of loneliness is reported to be $15-30 \%$ and the mean score of loneliness is $40.5^{18,19}$. Lauder et al. ${ }^{20}$ state that loneliness can be defined as a perception of social isolation, which poses serious health risks to the individual. In a study conducted in Australia, it was shown that lonely individuals tended to smoke more, have a higher body mass index, to be more overweight or obese, and less willing to make efforts for change ${ }^{20}$. Nausheen et al. ${ }^{21}$ stated that the feeling of loneliness impaired individual's ability to cope with stress by damaging their self-worth and self-efficacy, which worsened the effects of stress on the body. In another study, it was shown that high loneliness score affected the variables of age, smoking or body mass index, as well as increasing diastolic blood pressure in women ${ }^{22}$. Stickley et al. ${ }^{23}$ found that the feeling of loneliness was correlated with substance abuse and DeWall et al. ${ }^{24}$ found a correlation with higher nicotine consumption. In our study, the mean loneliness scores were lower 
than in other studies, but higher in the smokers group compared to others. Humans are prone to change by nature, therefore, once an individual makes their mind to quit smoking, a cessation treatment should be started as soon as possible. Smoking cessation treatments can be tailored based on results of psychometric evaluations through: goal setting, self-monitoring, and skills training related to coping with smoking urge; social support (provision of encouragement, caring, and information); and motivational interviewing techniques to develop a personalized cessation plan ${ }^{25}$. Cessation therapy in outpatient clinics involves restructuring and reorganizing the lifestyle on an individual basis, therefore discussions and valid questionnaires on the theme of loneliness during interviews may help us to better connect with patients to find more effective ways to improve their health status. For example, if the reason behind the loneliness is in fact uncontrolled diabetes or another disease, by way of preventive and therapeutic interventions, solutions could be found for personal problems. Giving thought to how and why our patients are lonely may help us prescribe practical solutions to expand opportunities of finding social support and thereby ensure the continuation of the conversation. This in turn is expected to increase patient compliance with the smoking cessation treatment.

It was observed that support from family, friends, colleagues and group support meetings facilitated cessation ${ }^{8,9}$. While higher rates of smoking were found in circles with poor socioeconomic circumstances, meager social support, and chronic unemployment. Women were reported to smoke to cope with stress and relax ${ }^{26}$. It was observed that an individual's likelihood to continue smoking decreased from $67 \%$ to $25 \%$ after their partner, friend, or sibling quit ${ }^{6}$. It was found that smokers benefited more from the strength of a united family in difficult times, a vision of success and hope for the future, and support from the social environment ${ }^{27}$. The role of family and social environment are undoubtedly important both in smoking and quitting. Similarly, in our study, while the scores of social support were higher in non-smokers, their loneliness score was found to be lower than in smokers. Studies have demonstrated the long-term benefits of social support services through telephone and internet counseling provided by healthcare workers ${ }^{27,28}$. Family and friends can support the use of drugs during smoking cessation (both a possible chronic disease and drugs given for smoking cessation), helping them cope with withdrawal symptoms, and providing emotionally effective support during smoking cessation, increasing the success of smoking cessation ${ }^{29,30}$. In terms of smoking cessation or considering a change in smoking habits, it might be beneficial to provide social support programs by healthcare workers, based on the individual needs defined with psychometric tests, especially for the success of tobacco control programs in developing countries.

In a large-scale study conducted in England, smoking cessation rates were found to be higher in individuals with no mental illness or receiving therapy for mental illness ${ }^{31}$. Another study found that scores decreased as the rate of smoking increased $^{32}$. In our study, even though there was no significant difference in terms of smoking rates, the mean mental wellbeing score was found higher in non-smokers. In our study the mean FTND score was $8.31 \pm 1.62$. As FTND scores increased, mean mental wellbeing scores decreased. Smoking cessation treatment is a process that requires long-term compliance and effort. Mental wellbeing can play an important role in helping people stay on this path. Perseverance is bound to increase smoking cessation rates.

\section{Limitations}

There were limitations in our study. The fact that it was restricted to the applicants of one hospital and that responses by individuals already applying with complaints would inevitably reflect instant negative emotions could bias the results. The same study conducted with home visits on a wider base might help people reveal their genuine emotions. In our study, those with chronic illness had higher smoking prevalence. This might have been an effect rather than a cause of their smoking habit. Our study population was relatively young so the patients might not yet have developed sufficiently serious health outcomes that could trigger quit attempts and result in a higher ex-smoker prevalence. Lack of basic details about smoking habits (the age the person started smoking, for how many years and how much they smoked, 
etc.) and limiting the questions to information about smoking criteria are study characteristics in need of improvement. Passive smoking was defined as involuntary exposure to the smoking of others. Unfortunately, the presence of smokers in the household and their influence on the smoking status of the participants were not investigated. Our study can provide a different perspective on smoking cessation treatments and provide ideas for studies to be planned with a wider population.

\section{CONCLUSION}

Relations were explored between the tests performed for psychological evaluations in order to determine the smoking status and degrees of addiction of the participants. An individual's ability to effectively benefit from social support resources may be related to their success in social relations and how they evaluate their living conditions. In the centers providing smoking cessation support as part of tobacco control programs, customizing the cessation treatment with the help of psychometric evaluations according to the smoking status may produce positive results for the continuity of the treatment program. Customizing treatment based on the results of these preliminary evaluations and contact with the individual's close relations can increase the rate of success in smoking cessation programs by assisting decision-making processes.

\section{REFERENCES}

1. Global Health Organization. The Global Health Observatory. https://www.who.int/data/gho/ghosearch?indexCatalogue $=$ ghosearchindex\&searchQuery $=$ Prevalence $\% 20$ of $\% 20$ tobacco $\% 20$ smoking\&wordsMode= AllWords\&orderBy $=$ Relevance\&language $=$ en. Accessed May 20, 2018.

2. Zincir BS, Zincir N, Sünbül AE, Kaymak E. Relationship between nicotine dependence and temperament and character traits in adults with cigarette smoking. J Mood Disor. 2012;2(4):160-166. doi:10.5455/jmood.20121010061050

3. Rezvanfard M, Ekhtiari H, Mokri A, Djavid G, Kaviani H. Psychological and behavioral traits in smokers and their relationship with nicotine dependence level. Arch Iran Med. 2010;13(5):395-405. PMID:20804306.

4. Cosci F, Pistelli F, Lazzarini N, Carrozzi L. Nicotine dependence and psychological distress: outcomes and clinical implications in smoking cessation. Psychol Res Behav Manag. 2011;4:119-128. doi:10.2147/PRBM.S14243

5. Gurpegui M, Jurado D, Luna JD, Fernández-Molina
C, Moreno-Abril O, Gálvez R. Personality traits associated with caffeine intake and smoking. Prog Neuropsychopharmacol Biol Psychiatry. 2007;31(5):9971005. doi:10.1016/j.pnpbp.2007.02.006

6. Christakis NA, Fowler JH. The collective dynamics of smoking in a large social network. N Engl J Med. 2008;358(21):2249-2258. doi:10.1056/NEJMsa0706154

7. Swami V, Chamorro-Premuzic T, Sinniah D, et al. General health mediates the relationship between loneliness, life satisfaction and depression. A study with Malaysian medical students. Soc Psychiatry Psychiatr Epidemiol. 2007;42(2):161-166. doi:10.1007/s00127-006-0140-5

8. LaChance H, Cioe PA, Tooley E, Colby SM, O'Farrell TJ, Kahler CW. Behavioral couples therapy for smoking cessation: A pilot randomized clinical trial. Psychol Addict Behav. 2015;29(3):643-652. doi:10.1037/adb0000051

9. Butler KM, Hedgecock S, Record RA, et al. An evidencebased cessation strategy using rural smokers' experiences with tobacco. Nurs Clin North Am. 2012;47(1):31-43. doi:10.1016/j.cnur.2011.10.008

10. Cook BL, Wayne GF, Kafali EN, Liu Z, Shu C, Flores $\mathrm{M}$. Trends in smoking among adults with mental illness and association between mental health treatment and smoking cessation. JAMA. 2014;311(2):172-182. doi:10.1001/jama.2013.284985

11. Yañez AM, Bennasar-Veny M, Leiva A, García-Toro M. Implications of personality and parental education on healthy lifestyles among adolescents. Sci Rep. 2020;10(1):7911. doi:10.1038/s41598-020-64850-3

12. Doğanay S, Sözmen K, Kalaça S, Ünal B. How has the prevalence of smoking changed in Turkey?. Turkish Journal of Public Health. 2012;10(2):93-115. doi:10.20518/tjph.173069

13. Russell D, Peplau LA, Ferguson ML. Developing a measure of loneliness. J Pers Assess. 1978;42(3):290294. doi:10.1207/s15327752jpa4203_11

14. Zimet GD, Dahlem NW, Zimet SG, Farley GK. The Multidimensional Scale of Perceived Social Support. Journal of Personality Assessment. 1988;52(1):30-41. doi:10.1207/s15327752jpa5201_2

15. Tennant R, Hiller L, Fishwick R, et al. The WarwickEdinburgh Mental Well-being Scale (WEMWBS): development and UK validation. Health Qual Life Outcomes. 2007;5(1):63. doi:10.1186/1477-7525-5-63

16. Fagerström KO. Measuring degree of physical dependence to tobacco smoking with reference to individualization of treatment. Addict Behav. 1978;3(3-4):235-241. doi:10.1016/0306-4603(78)90024-2

17. Basu S, Yadav P, Banerjee B, Yadav A. The effect of a clinic-based behavioral intervention in promoting enrolment in a text-message tobacco cessation program at a rural primary health clinic in Delhi, India. Tob Prev Cessation. 2020;6(May):1-7. doi:10.18332/tpc/120382

18. Heinrich LM, Gullone E. The clinical significance of loneliness: a literature review. Clin Psychol Rev. 
2006;26(6):695-718. doi:10.1016/j.cpr.2006.04.002

19. Geller J, Janson P, McGovern E, Valdini A. Loneliness as a predictor of hospital emergency department use. J Fam Pract. 1999;48(10):801-804. PMID:12224678.

20. Lauder W, Mummery K, Jones M, Caperchione C. A comparison of health behaviours in lonely and non-lonely populations. Psychol Health Med. 2006;11(2):233-245. doi:10.1080/13548500500266607

21. Nausheen B, Gidron Y, Gregg A, Tissarchondou HS, Peveler R. Loneliness, social support and cardiovascular reactivity to laboratory stress. Stress. 2007;10(1):37-44. doi:10.1080/10253890601135434

22. Steptoe A, Owen N, Kunz-Ebrecht SR, Brydon L. Loneliness and neuroendocrine, cardiovascular, and inflammatory stress responses in middle-aged men and women. Psychoneuroendocrinology. 2004;29(5):593611. doi:10.1016/S0306-4530(03)00086-6

23. Stickley A, Koyanagi A, Koposov R. Stone MS, Ruchkin $\mathrm{V}$. Loneliness and health risk behaviours among Russian and U.S. adolescents: a cross-sectional study. BMC Public Health. 2014;14(1):366. doi:10.1186/1471-2458-14-366

24. DeWall CN, Pond RS. Loneliness and smoking: The costs of the desire to reconnect. Self and Identity. 2011;10(3):375385. doi:10.1080/15298868.2010.524404

25. Lepore SJ, Collins BN, Sosnowski DW. Self-efficacy as a pathway to long-term smoking cessation among lowincome parents in the multilevel Kids Safe and Smokefree intervention. Drug Alcohol Depend. 2019;204:107496. doi:10.1016/j.drugalcdep.2019.05.027

26. Hutcheson TD, Greiner KA, Ellerbeck EF, Jeffries SK, Mussulman LM, Casey GN. Understanding smoking cessation in rural communities. J Rural Health. 2008;24(2):116-124. doi:10.1111/j.1748-0361.2008.00147.x

27. Cupertino AP, Mahnken JD, Richter K, et al. Long-term engagement in smoking cessation counseling among rural smokers. J Health Care Poor Underserved. 2007;18(Suppl 4):39-51. doi:10.1353/hpu.2007.0117

28. Bullock L, Everett KD, Mullen PD, Geden E, Longo DR, Madsen R. Baby BEEP: A randomized controlled trial of nurses' individualized social support for poor rural pregnant smokers. Matern Child Health J. 2009;13(3):395-406. doi:10.1007/s10995-008-0363-z

29. Westmaas JL, Bontemps-Jones J, Bauer JE. Social support in smoking cessation: reconciling theory and evidence. Nicotine Tob Res. 2010;12(7):695-707. doi:10.1093/ntr/ntq077

30. Aschbrenner KA, Naslund JA, Gill L, Bartels SJ, O'Malley AJ, Brunette MF. preferences for smoking cessation support from family and friends among adults with serious mental illness. Psychiatr Q. 2017;88(4):701-710. doi:10.1007/s11126-016-9485-4

31. Gireesh A, Das S, Viner RM. Impact of health behaviours and deprivation on well-being in a national sample of English young people. BMJ Paediatrics Open. 2018;2(1):e000335. doi:10.1136/ bmjpo-2018-000335

32. Stranges S, Samaraweera PC, Taggart F, Kandala NB,
Stewart-Brown S. Major health-related behaviours and mental well-being in the general population: the Health Survey for England. BMJ Open. 2014;4(9):e005878. doi:10.1136/bmjopen-2014-005878

\section{ACKNOWLEDGEMENTS}

Thanks to all the participants who agreed to participate in our work.

\section{CONFLICTS OF INTEREST}

The authors have completed and submitted the ICMJE Form for Disclosure of Potential Conflicts of Interest and none was reported.

\section{FUNDING}

There was no source of funding for this research.

\section{AUTHORS' CONTRIBUTIONS}

SG had the original idea for the study. MK coordinated the data collection in the field. BRE carried out the analysis. SG wrote the manuscript in collaboration with all other authors. All the authors made substantial contributions to conception, design, and interpretation of data. All the authors contributed to manuscript preparation and approved its final version.

\section{PROVENANCE AND PEER REVIEW}

Not commissioned; externally peer reviewed. 